\title{
OSTEOCONDROMATOSE MÚLTIPLA HEREDITÁRIA COM ENVOLVIMENTO COSTAL
}

\author{
RIB INVOLVEMENT IN HEREDITARY MULTIPLE OSTEOCHONDROMATOSIS
}

\author{
Raul Lopes Ruiz Jr., ACBC-SP1; Fernando Geraldi Dias, ACBC-SL ${ }^{2}$; Ricardo Lucatto Baida ${ }^{2}$; \\ Daniele Cristina Cataneo ${ }^{1}$; Antonio José Maria Cataneo, TCBC-SP ${ }^{3}$
}

\section{INTRODUÇÃO}

A Osteocondromatose Múltipla Hereditária (OMH) é uma desordem do crescimento ósseo endocondral manifestada por proeminências anormais no osso metafisário, recobertas com cartilagem e acompanhadas por defeitos que remodelam e retardam o crescimento ósseo longitudinal. Muitos são os sinônimos para esta doença. Os mais freqüentemente usados são: Exostose e Osteocondromatose Múltipla Hereditária $(\mathrm{OMH})^{1}$.

São as anormalidades do desenvolvimento do esqueleto mais frequientes. A prevalência é aproximadamente de um para 50.000 indivíduos. As lesões raramente estão presentes ao nascimento. Na primeira década de vida são diagnosticados $80 \%$ dos casos ${ }^{1}$.

O padrão de herança é definido por gene autossômico dominante com penetração completa. Em metade da prole, cujos pais carregam este gene, são expressas essas características. Na maioria dos portadores há envolvimento de outros membros da família. Não existe predileção por gênero. Nas mulheres existe uma expressão reduzida, com menor envolvimento e menor manifestação clínica² ${ }^{2}$.

Os ossos mais comumente acometidos são os tubulares, escápula, pélvis e costelas. Apresentam menor envolvimento: carpo, tarso, patela, esterno, crânio, corpos vertebrais.

O tratamento cirúrgico está indicado quando há dor, irritação dos tecidos adjacentes, distúrbio do crescimento causando deformidade ou encurtamento dos membros, comprometimento da movimentação das articulações, compressão dos tendões, nervos periféricos, vasos e canal medular ${ }^{2}$. Associadas às lesões costais podem ocorrer complicações como a dor pleural por irritação ${ }^{2,3}$, além de hemotórax ou pneumotórax em decorrência da fratura da lesão ou espículas ósseas com perfuração do pulmão $0^{3,4}$ e diafragma ${ }^{5}$. Os autores descrevem o caso clínico de um paciente com osteocondromatose múltipla hereditária.

\section{RELATO DO CASO}

Paciente do sexo masculino, 23 anos. Queixou-se de aparecimento de "caroços" pelo corpo há cinco anos. Na região dorsal direita estes são maiores, dolorosos e quentes.
Nega qualquer antecedente pessoal mórbido. Refere tios paternos com problemas idênticos. Seu irmão apresentou nodulações endurecidas nas pernas. Tio falecido por neoplasia óssea maligna.

Ao exame físico presença de lesões tumorais ósseas em região posterior do ombro direito, radio distal e pé direitos. Todos sem sinais flogísticos, sem dor à palpação ou limitação à movimentação. Presença de hálux direito e esquerdo valgos, membros superiores e inferiores encurtados.

Os exames de imagens do tórax mostravam que as lesões acometiam as regiões posteriores $\operatorname{dos} 2^{\circ}, 3^{\circ}$ e $4^{\circ}$. $\operatorname{arcos}$ costais (Figura 1 - A, B, C e D).

Ador, bem como a deformidade torácica (Figura 2 - A e B), motivaram o paciente a procurar o serviço.

\section{ATO OPERATÓRIO}

A incisão da pele e do tecido celular subcutâneo estendia-se da porção superior da região inter-escápulo-vertebral até $4 \mathrm{~cm}$ abaixo do ângulo da escápula direita acompanhando sua borda medial.

Após secção do músculo trapézio, medialmente à escápula, foram observadas as lesões recobertas pelo plano dos músculos rombóides maior e menor, inferiormente, e superiormente pelo levantador da escápula, que foram seccionados evidenciando os tumores (Figura $2-\mathrm{C}$ ).

A dissecção cuidadosa e ligadura das artérias intercostais, referentes a cada um dos arcos costais, foram realizadas. Então estes foram seccionados com margem operatória de $2 \mathrm{~cm}$ de cada lado dos tumores (Figura $2-\mathrm{D}$ ), sem que tenha havido lesão da pleura visceral.

Finalmente foi realizada a síntese dos planos da ferida operatória.

\section{ANÁTOMO-PATOLÓGICO}

O exame macroscópico evidenciou dois tumores, em forma de cogumelo, crescendo a partir de fragmentos, um do $2^{\circ}$. e o outro dos $3^{\circ}$. e $4^{\circ}$. arcos costais. Ambos apresentavam aspecto lobulado, amarelo-esbranquiçado, medindo e pesando respectivamente, $4,5 \times 3,0 \mathrm{~cm}$ com $55 \mathrm{~g}$ e $6,5 \times 5 \mathrm{~cm}$ com $61,9 \mathrm{~g}$. Aos cortes o aspecto era variegado com áreas superficiais

\footnotetext{
1. Professor Assistente da Disciplina de Cirurgia Torácica do Departamento de Cirurgia e Ortopedia da Faculdade de Medicina de Botucatu - Unesp.

2. Médicos Residentes da Disciplina de Cirurgia Torácica do Departamento de Cirurgia e Ortopedia da Faculdade de Medicina de Botucatu - Unesp.

3. Professor Adjunt Disciplina de Cirurgia Torácica do Departamento de Cirurgia e Ortopedia da Faculdade de Medicina de Botucatu - Unesp.

Recebido em 19/01/2006

Aceito para publicação em 16/03/2006

Trabalho realizado na Disciplina de Cirurgia Torácica do Departamento de Cirurgia e Ortopedia da Faculdade de Medicina de Botucatu - Unesp.
} 

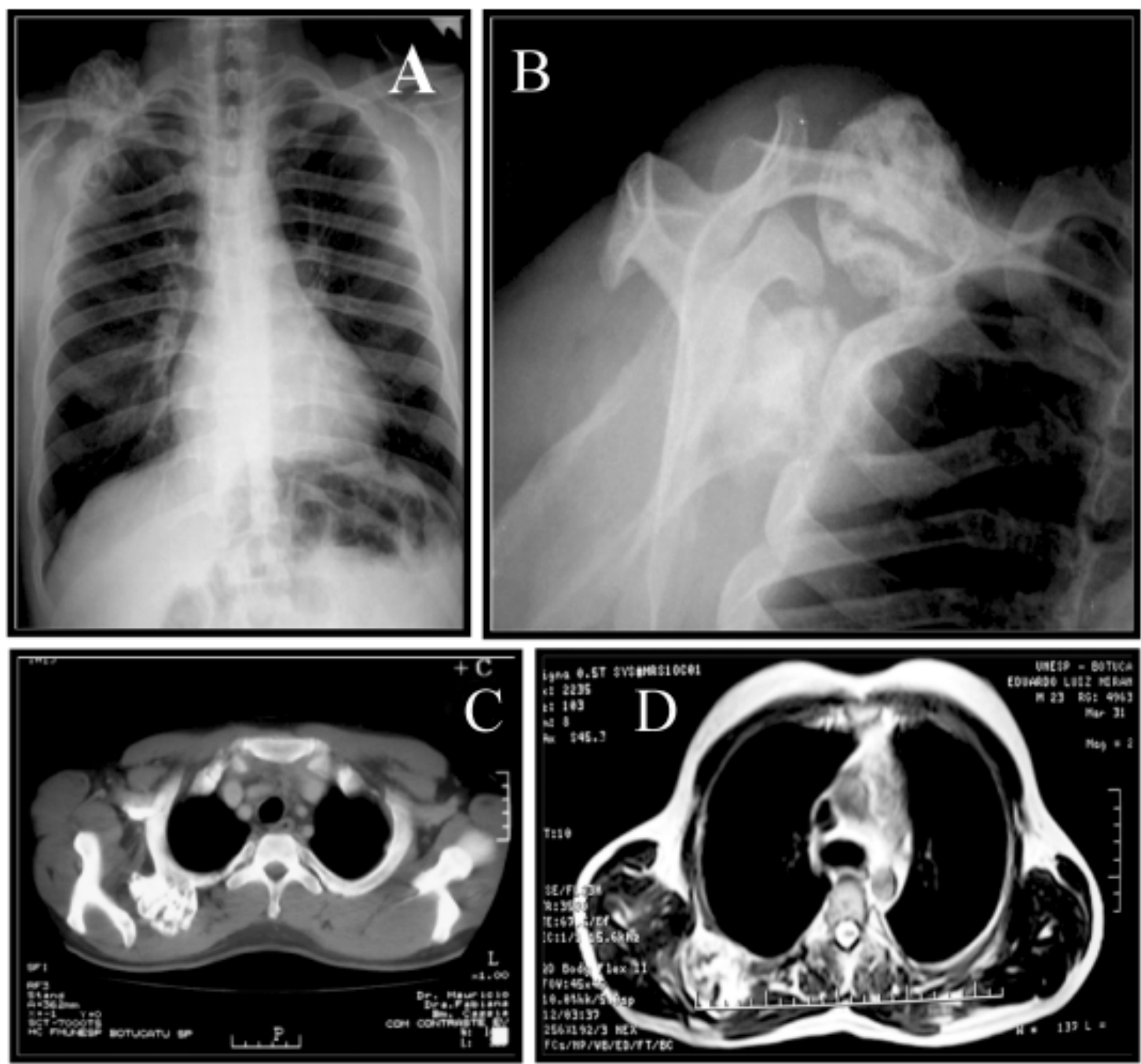

Figura 1 - A: exame radiológico do tórax em póstero-anterior com a presença de tumores ossificados em regiões posteriores dos $2^{\circ}$. , $3^{\circ}$. e $4^{o}$. arcos costais à direita. B: exame radiológico do tórax, em detalhe os tumores nos $2^{o}$. e $3^{o}$. e $4^{o}$. arcos costais à direita. C: exame tomográfico do tórax, presença de tumor com origem nos arcos costais, sem invasão dos tecidos adjacentes. D: corte de ressonância nuclear magnética do tórax com melhor detalhamento das relações dos tumores com os tecidos adjacentes.

compactas e alveolares centralmente, recobertos por capuz cartilaginoso.

A microscopia mostrou capuz composto por cartilagem hialina benigna recoberto perifericamente por pericôndrio. Essa cartilagem apresentava aspecto de placa de crescimento desorganizado, sofrendo ossificação endocondral. Os córtices dos tumores se confundiam com os dos ossos hospedeiros, formando cavidades medulares contínuas.

\section{DISCUSSÃO}

$\mathrm{Na} \mathrm{OMH}$ cerca de $40 \%$ dos portadores apresentam envolvimento costal. Nos adultos as fraturas das lesões propiciam a formação fragmentos afilados ou a própria exostose em formato de espícula, podem provocar perfurações da pleura visceral ou parietal, causando pneumotórax e hemotórax, respectivamente ${ }^{3,4}$. Na infância e adolescência a ocorrência de abrasão da pleura visceral adjacente às lesões, durante os movimentos respiratórios, leva ao processo irritativo manifestando-se com dor pleurítica persistente ${ }^{3}$.

Tanto o pneumotórax quanto o hemotórax são complicações pouco comuns. Foram descritos apenas em homens jovens ${ }^{3,4,5}$, mostrando que são mais acometidos pela doença e suas complicações. Nos relatos da literatura o acometimento costal não ocorreu no gênero feminino ${ }^{3}$. $\mathrm{Na} \mathrm{OMH}$ a indicação de ressecção de lesões foi cinco vezes menor nas mulheres ${ }^{3}$.

Este paciente é proveniente de família cujos tios e irmão apresentaram manifestações da doença, porém apenas ele tinha envolvimento costal. As lesões eram localizadas posteriormente, nos $2^{\circ}$., $3^{\circ}$. e $4^{\circ}$. arcos, arredondadas, com a superfície lisa (Figura 2 - C e D), sem proeminências pontiagudas capazes de lesionar a pleura parietal ou perfurar a visceral.

Acreditamos que, nos pacientes do gênero masculino, a ressecção do segmento costal acometido deva ser realizada preventivamente, evitando as complicações ${ }^{3,4,5}$. 

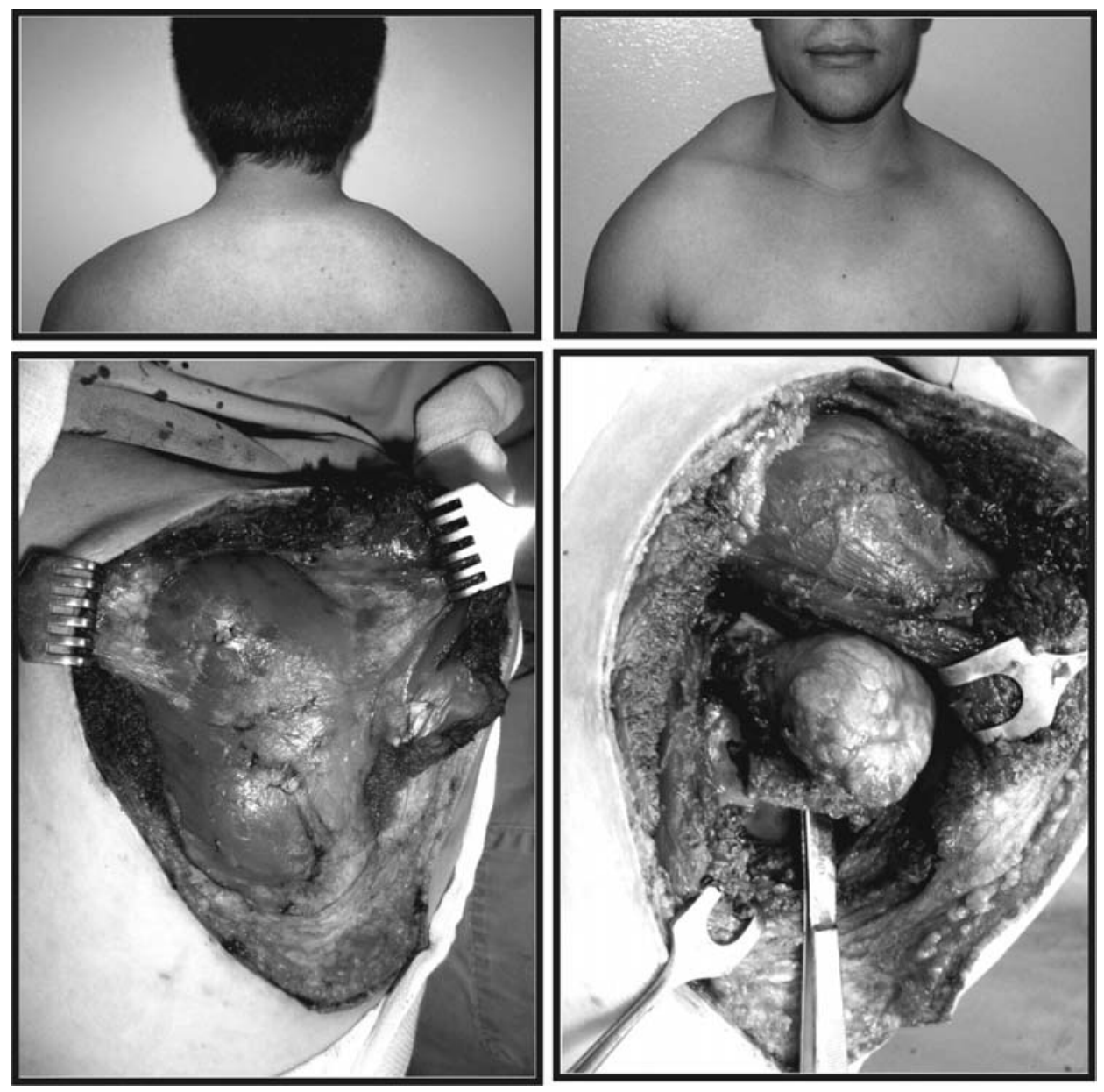

Figura 2 - A: elevação que se extende da região superior do ombro direito, ocupando toda a região interescapulovertebral direita. B: visão anterior do tórax com elevação sobre o ombro direito. $\boldsymbol{C}$ : abertura dos planos mais superficiais mostrando os tumores recobertos por plano muscular mais profundo. D: superiormente vê-se a lesão no $2^{\circ}$. arco, ainda recoberto por plano muscular. Abaixo, ressecção do tumor acometendo os $3^{\circ}$. e $4^{\circ}$. arcos costais.

\begin{abstract}
This is a case report on Hereditary Multiple Osteochondromatosis (HMO) with rib involvement. The authors present aspects of thoracic surface anatomy, and thoracic images (X-rays, computed tomography, magnetic nuclear resonance), as well as the operating procedure (Rev. Col. Bras. Cir. 2008; 35(4): 277-279).
\end{abstract}

Key words: Exostoses, multiple hereditary; Osteochondromatosis; Bone neoplasms; Tomography, X-Ray Computed.

\section{REFERÊNCIAS}

1. Solomon L. Hereditary multiple exostosis. J Bone Joint Surg. 1963;45B(2):292-304.

2. Darilek S, Wicklund C, Novy D, Scott A, Gambello M, Johnston D, Hecht J. Hereditary multiple exostosis and pain. J Pediatr Orthop. 2005;25(3):369-76.

3. Nick JA, Lynch DA, Schwarz MI, Hanley ME. A thoracic complication of hereditary multiple exostoses in an adult. Respir Med. 1999;93(3):217-9.

4. Uchida K, Kurihara Y, Sekiguchi S, Doi Y, Matsuda K, Miyanaga M, Ikeda Y. Spontaneous haemothorax caused by costal exostosis. Eur Respir J. 1997;10(3):735-6.

5. Simansky DA, Paley M, Werczberger A, Bar Ziv Y, Yellin A. Exostosis of a rib causing laceration of the diaphragm: diagnosis and management. Ann Thorac Surg. 1997;63(3):856-7.
Como citar este artigo:

Ruiz Jr. RL, Dias FG, Baida RL, Cataneo DC, Cataneo AJM. Osteocondromatose múltipla hereditária com envolvimento costal. Rev Col Bras Cir. [periódico na Internet] 2008; 35(4). Disponível em URL: http://www.scielo.br/rcbc

Endereço para correspondência:

Prof. Dr. Raul Lopes Ruiz Jr.

Caixa Postal, 501

Botucatu-SP

CEP: $18618-970$

E-mail: ruizraul@fmb.unesp.br 